\title{
Ensino Remoto Desenvolvido em Escolas Indígenas Potiguara da Paraíba
}

\author{
Leonardo Cinésio Gomes ${ }^{1}$, Iranilda Cinésio Gomes² \\ ${ }^{1}$ Departamento de Ciências Exatas -Universidade Federal da Paraíba (UFPB) \\ Rio Tinto - PB-Brasil \\ ${ }^{2}$ Uniasselvi- centro Universitário Leonardo Da Vinci \\ Polo Mamanguape-PB- Brasil \\ leocinesio@gmail.com, iranildacinesio@gmail.com
}

\begin{abstract}
This research aims to socialize for the academic community the importance of differentiated education for indigenous peoples and the impacts suffered in this education with the social isolation caused by the pandemic caused by the new corona virus Covid-19, with a focus on the Potiguara Peoples of Paraíba, indigenous schools struggle for their autonomy. These schools operate with differentiated education, these schools have their target audience indigenous. As a methodology, a case study and bibliographic and qualitative research were chosen. Schools, teachers and students were not prepared for this challenge, they all had to reinvent themselves to overcome this challenge.
\end{abstract}

Resumo Esta pesquisa tem como finalidade socializar para a comunidade acadêmica a importância da educação diferenciada para os povos indígenas e os impactos sofridos nesta educação com o isolamento social causado pela pandemia decorrente do novo corona vírus Covid-19, com foco nos Povos Potiguara da Paraíba, as escolas indígenas lutam por sua autonomia. Essas escolas atuam com ensino diferenciado, essas escolas têm seu publico alvo indígenas. Como metodologia optou-se por estudo de caso e pesquisa bibliográfica e qualitativa. As escolas, professores e estudantes não estavam preparados para esse desafio, todos tiveram que se reinventar, para superar mais esse desafio.

\section{Educação escolar indígena e Tecnologias na Educação}

Esta pesquisa tem como finalidade socializar para a comunidade acadêmica a importância da educação diferenciada para os povos indígenas e os impactos sofridos nesta educação com o isolamento social causado pela pandemia decorrente do novo corona vírus Covid-19, com foco nos Povos Potiguara da Paraíba, localizados no litoral do estado da Paraíba.

Para iniciamos um dialogo sobre a educação escolar indígena devemos destacar alguns fatos históricos, pois essa educação inicia com a intervenção dos jesuítas em meados do século XVI. 
Antes da formulação de leis que tratam oficialmente da educação escolar indígena, em meados do século XVI, a mesma era oferecida pelos jesuítas, pautada na catequização, civilização e integração forçada dos índios à sociedade nacional. Este sistema educacional negava a identidade indígena e tentava transformar os índios em seres diferentes do que eram. [Fustino, 2006]

Neste sentido os indígenas foram obrigados a educação escolar, como também foram obrigados a negar sua identidade radicalizando os indígenas forçando os indígenas a ignorar sua cultura, suas crenças e suas particularidades aos poucos foram sendo integrados a sociedade nacional.

Ao longo dos anos a escola chega ás comunidades indígenas, com um ensino formal, desconsiderando as características culturais do local onde está inserida. Os indígenas não sabiam qual a serventia da escola e a escola não desempenhava um papel de protagonismo dos indígenas, pelo contrario desconstruía a crença desse povo.

A criação da Constituição Federal aconteceu quando já não tinha a interferência da igreja católica por meio dos jesuítas, na Constituição Federal está disposto um artigo que garante a educação a todos e obriga o estado a oferta desta educação.

De acordo (BRASIL, 1988) o artigo 205 da Constituição Federal de 1988 a educação é direito de todos e dever do Estado. Será promovida e incentivada visando ao pleno desenvolvimento da pessoa, com o objetivo de preparo para o exercício da cidadania e sua qualificação para o trabalho, devendo-se exigir à prática educativa e igualitária, fazendo assim com que todos tenham condições necessárias para buscarem sua formação, desta forma desenvolvendo a liberdade de apreender, ensinar, pesquisar e divulgar os pensamentos a arte e o saber.

As escolas indígenas lutam por sua autonomia. No estado da Paraíba, atualmente conta com 11 escolas estaduais indígenas com ensino diferenciado, essas escolas tem seu publico alvo alunos indígenas, corpo docente e pessoal de apoio também indígenas da etnia potiguara, essas escolas possuem um calendário diferenciados levando em consideração as especificidades deste povo. As aulas são lecionadas em um viés cultural e espiritual buscando a autonomia cultural dos estudantes.

De acordo com Gonçalves e Mello, (2009), a educação indígena se caracteriza pelos procedimentos tradicionais de aprendizagem de saberes, costumes e ritos característicos de cada povo, de cada etnia. Estes conhecimentos são ensinados de forma oral no dia-a-dia, nos rituais e nos mitos passados de geração em geração. Entretanto, várias etnias indígenas têm buscado a educação escolar como um instrumento de redução da desigualdade, como é o caso dos Povos Potiguara da Paraíba para a firmação de direitos e conquistas e de promoção do diálogo intercultural entre diferentes agentes sociais.

Alem de todo componente curricular obrigatório nas escolas não indígenas, nas escolas de ensino diferenciado, são ofertadas as disciplina obrigatórias Língua Tupi Antigo, Artes-Cultura e Etno-História (legislação e antropologia indígena), são realizadas frequientes aulas a campo mostrando as matas, os mangues e mares destacando a importância da sua preservação além de mostrar a relação que o povo tem com esses espaços, que são ambientes sagrados para o povo Potiguara, são realizadas também palestras com os anciões, cacique e pajés. 
Educação indígena, no seu sentido mais amplo, tem como objetivo a transmissão e a consequente partilha dos costumes, das tradições, da língua e de tudo o que for próprio de uma comunidade indígena em particular. Porém, se através da educação própria do índio, compartilham-se saberes, fazeres, também compartilham-se abandono, desvalorização cultural e, consequentemente, perda da língua, da cultura e da identidade. [Bello, 1996, p.104].

Nesse sentido, a educação indígena é feita a partir de partilhas, das tradições e da língua de um povo que compartilham dos seus saberes, mantendo vivos seus costumes.

Em consonância com a cultura indígena os professores tentam ao máximo introduzir a cultura digital de forma consciente para sua comunidade estudantil. Utilizando sempre que possível tecnologia voltada a métodos educacionais. Um desafio grande, pois as aldeias por estarem situadas na zona rural nem todas tem a cesso a internet e quando se tem o acesso, esse não é de boa qualidade, nem todas as escolas dispõem de laboratório de informática. Outra questão é a formação dos professores para atuar com as tecnologias digitais voltadas para a educação.

Sabemos que a tecnologia está em todo lugar é de extrema importância seu uso, nos grandes centros urbanos como na zona rural, na produção das indústrias na cidade como na fazenda nas plantações e no sítio.

No contexto escolar não é diferente, o uso da tecnologia é indispensável, estando ligada diretamente com a parte burocrática e gerencial da escola, facilitando seus serviços, na realização e renovação de matriculas, registro de avaliações, aula e frequência, através dos diários online dos professores, facilitando $\mathrm{o}$ ensino aprendizagem dos alunos, seja ele com o uso de softwares educacionais, TV, computador, uso de aplicativos nos celulares dos alunos e plataformas que auxiliam na aprendizagem.

Mesmo diante do exposto nem todas as escolas dispõem de uma boa conexão com a internet e/ou um laboratório de informática e de uma quantidade de computadores adequada.

O reconhecimento de uma sociedade cada vez mais tecnológica deve ser acompanhado da conscientização da necessidade de incluir nos currículos escolares as habilidades e competências para lidar com as novas tecnologias. No contexto de uma sociedade do conhecimento, a educação exige uma abordagem diferente em que o componente tecnológico não pode ser ignorado. [Mercado, 2002, p. 11].

Neste contexto temos que o computador assim como outros dispositivos digitais são de extrema importância em sala de aula.

De acordo com Silva (2011) existe uma grande preocupação por parte de pesquisadores na área da educação, um grande número de pesquisas com foco na utilização de tecnologia, de softwares, do uso de blogs, da webquest, buscando formas que estimulem o conhecimento dos alunos através do uso dos recursos digitais.

\section{Povo Potiguara da Paraíba}


De acordo com Nascimento e Barcellos (2012), a palavra Potiguara, tem origem do tupi antigo e em português, significa "povo comedor de camarão". São aqueles que habitam as terras de Akajutibiró palavra de origem do tupi antigo ("caju azedo ou bravo"), refere-se ao antigo nome da cidade da Baía da Traição-PB. Hoje, Akajutibiró é o nome de umas das aldeias pertencentes ao município da Baía da Traição. Esse povo resistem desde 1501, o povo Potiguara ocupavam um território amplo que abrangia a costa do nordeste, entre as cidades de Fortaleza/CE até João Pessoa/PB. Povo temido pelos seus inimigos pelos portugueses e outros povo indígenas eram conhecidos como guerreiros. No estado da Paraíba, ocupava todo o vale do rio Mamanguape, litoral norte, desde a Baia da Tradição até a atual Serra da Raiz (na época Serra da Cupaoba).

Segundo Barcellos (2012) os Potiguara têm população de aproximadamente, 20.000 mil indígenas, último levantamento realizado em 2012, nos dias atuais os Potiguara estão distribuídos em um território de 33.757 hectares, distribuídos em três áreas contíguas em apenas três municípios que são eles: Marcação, Baía da Traição e Rio Tinto, municípios situados no Litoral Norte do Estado da Paraíba.

De acordo com Nascimento e Barcellos (2012) cada aldeia indígenas Potiguara também chamada de comunidade indígena possui vida, autonomia e convenções próprias. São lideradas por um cacique (liderança) local e um cacique geral, sem restrição de sexo podendo ser do sexo masculino ou feminino que representa a aldeia diante da sociedade indígena e não indígena.

\section{Metodologia}

Sob o ponto de vista metodológico optou-se por uma pesquisa bibliográfica e de um estudo de caso. Como pesquisa bibliográfica para aprofundar o conhecimento sobre a área, e para a realização da fundamentação teórica a fim de conhecer o que já foi estudado e publicado, como estudo de caso, a fim de investigar sobre a Educação Escolar Indígena em tempo de Pandemia, para isso foi aplicado questionário online para oito professores do Ensino Infantil, Ensino Fundamental Anos Inicias e Anos Finais e Ensino Médio a fim de entender como estar acontecendo o ensino em plena pandemia do corona vírus Covid-19.

Em relação à abordagem do problema, trata-se de uma a pesquisa qualitativa, pois esse tipo de abordagem não requer o uso de técnicas estatísticas para quantificar a pesquisa. De acordo com Silva e Menezes (2005) a pesquisa é considerada qualitativa quando considerar que há uma relação dinâmica entre o mundo real e o sujeito, isto é, um vínculo indissociável entre o mundo objetivo e a subjetividade do sujeito que não pode ser traduzido em números.

Como campo e sujeitos da pesquisa o estudo foi realizado na Escola da Aldeia Brejinho, localizada na zona rural do município de Marcação-PB, a referida escola é estadual indígena atua com ensino diferenciado utilizando uma metodologia voltada para a autonomia e cultura do povo potiguara, a escola é um pólo sede no município uma vez que acolhe alunos de todas 15 aldeias existente no município alem de acolher alunos do centro da cidade.

A pesquisa intitulada Ensino Remoto Desenvolvido em Escolas indígenas Potiguara da Paraíba foi realizada durante o período de isolamento social mediante a pandemia do novo corona vírus Covid-19. Entre os meses de abril e março do ano de 2019.

\section{Inclusão digital na escola investigada}


A escola é considerada pela comunidade como grande por está localizada em uma aldeia, dispondo de sete salas de aulas, uma sala de professor, uma biblioteca e uma sala da direção, um laboratório de computação e um espaço destinado ao laboratório de matemática, física, química e robótica. A escola oferece o ensino desde o Ensino Infantil ao Ensino Médio atuando nos três horários, manhã, tarde e noite contando com uma média de 400 alunos regulamente matriculados.

O laboratório de informática possui dez computadores dos quais apenas seis funcionam, um projetor de imagem, uma TV de 50 polegadas, a internet tem um sinal péssimo, por esse fato é possível notar o quanto é difícil trabalhar com o ensino digital em ambiente como esse, o laboratório de informática, com seis computadores funcionando, certamente funciona apenas para pesquisas escolares.

Com um grande número de alunos e com um pequeno número de computadores, os professores dividem sua turma para utilização do laboratório de informática, fazendo com que a realização da atividade seja mais longa que o normal. Além de utilizar aplicativo nos smartphone pessoais dos alunos.

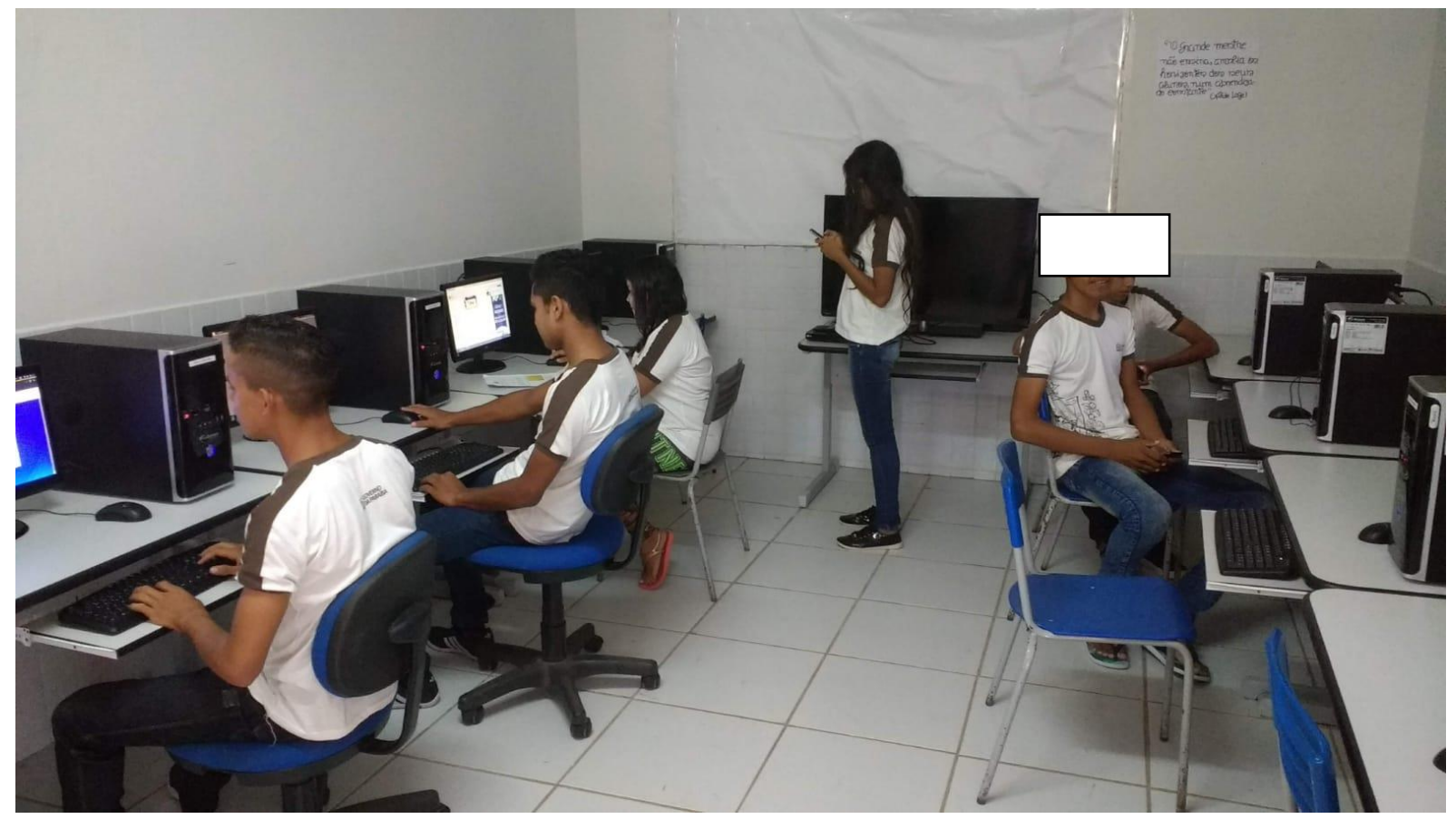

Figura 01- Realização de atividade da disciplina de Matemática 1ª Serie do Ensino Médio (2019) no laboratório de Informática

Fonte: GOMES, Leonardo Cinésio, Professor de Matemática (2019)

$\mathrm{Na}$ imagem é possível ver os alunos do Ensino Médio utilizando as ferramentas digitais, neste caso em uma aula de matemática utilizando o software livre Geogebra .

O Software GeoGebra é um aplicativo matemático dinâmica que combina conceitos de geometria e álgebra utilizando uma interfase em três dimensões-3D.

Assim como o professor de matemática outros professores vêm se esforçando ao máximo para a inserção das novas tecnologias nas aulas, mesmo diante de tantos empecilhos encontrados na realização dessas metodologias. 
As possibilidades que os professores têm para levarem a tecnologia para suas aulas é usar o projetor de imagem, reproduzir vídeos pela TV ou smartphone pessoais caso os alunos disponham desse aparelho ou dividir sua turma para uso dos computadores.

\section{Ensino Remoto em tempos de pandemia do novo corona vírus Covid-19}

No estado da Paraíba as aulas na rede estadual de ensino, assim como nas demais redes de ensino tanto pública como privada, foram suspensas desde o dia 19 de abril em decreto publicado em diário oficial publicado no dia 18 de abril.

$\mathrm{Na}$ rede estadual de ensino foi feita a antecipação de um mês de férias escolares. No mês de maio dia 27 é iniciada as aulas em regime especial de forma remota em todas as escolas estaduais da Paraíba.

De acordo com a coleta de dados os professores fizeram um curso a distancia de gestão de atividades remotas no regime especial com carga horária de 20 horas, no Google Classroom, plataforma disponibilizada para as realizações de atividades com os estudantes de todos os níveis de ensino ofertados na escola estadual.

A escola em que ocorreu a pesquisa a qual é da rede estadual de ensino, localizada na aldeia Brejinho município de Marcação também está funcionando com o ensino remoto.

Para conseguir desenvolver as atividades e alcançar o maior numero de alunos possíveis os professores estão fazendo uso de diversas ferramentas digitais como Gloogle Classrom, YouTube, e-mails, WhatsApp, entre outras ferramentas digitais. As atividades estão sendo auxiliadas pelos professores da disciplina para que os alunos tirem suas possíveis dúvidas, além de matérias impressos entregue aos alunos do Ensino Fundamental Anos Iniciais e Anos Finais assim como entregue as atividades impressas dos alunos do Ensino Infantil. Essas são as estratégias utilizadas pelos professores da escola da aldeia brejinho.

\section{Análise dos dados}

\subsection{Pesquisa com os professores da Educação Infantil ao Ensino Médio}

Perfil dos entrevistados

Foram entrevistados oito professores, cinco do sexo feminino e três do sexo masculino, todos formados na área de atuação, as experiências em sala de aula variam de 4 a 15 anos. As idades variam de 27 a 47 anos.

Todos os professores entrevistados pertencem a etnia Potiguara residem em aldeia, um na aldeia Alto da Tambá na cidade Baia da Traição, uma na aldeia Três Rios e seis na aldeia Brejinho ambas as aldeias situadas na cidade Marcação.

Nenhum professor entrevistados tinham experiência em ministrar aulas online, um entrevistado teve sua licenciatura virtual.

Concepções dos professores sobre as atividades remotas realizadas durante o período de isolamento social.

Dos oito professores entrevistados três afirmam que a formação que teve para atuar na plataforma Gloogle Classrom não foi suficiente, tendo duvidas como gerenciar a ferramenta. 
Todos os oitos professores falam que não realizaram ate o momento vídeo conferência por saber da má qualidade da internet dos alunos, acham pertinente essa comunicação como uma forma de fortalecimento de vinculo neste momento difícil em que o Brasil e o mundo passa. Relatam que apenas $10 \%$ dos alunos estão realizando as atividades e que os outros não estão devido a falta de internet, por muitas das aldeias não terem acesso a internet, e/ou por condições financeira dos pais. Esse fato ocorre nas turmas do Ensino Médio, uma vez que o ensino fundamental Anos Iniciais e Anos Finais o material e entregue impresso para os alunos.

De acordo com os entrevistados esse fato ocorre pelo fato de que os alunos do Ensino Médio em sua maioria são de outras aldeias, impossibilitando a entrega das atividades serem impressas.

Dos $10 \%$ dos alunos que estão entregando as atividades de forma online nem todos são pela plataforma, uns por que o telefone celular não suporta o Gloogle Classro, ou pela internet não ser suficiente para acessar a plataforma, desta forma um parte dessas atividades são realizadas através de aplicativos de mensagem ou rede sociais como o WhatsApp.

Os alunos sentem dificuldades em assistir aos vídeos aulas disponibilizados pelos professores assim surgem muitas duvidadas referente ao assunto ministrado.

Com isso é possível ver os danos catastróficos na Educação escolar indígena da Paraíba uma vez que os professores e nem os alunos estavam preparados para um a educação a distancia mesmo que remota, os alunos não dispõem de aplicativos e/ou internet para a realização das atividades.

Os professores têm a educação remota como desafiadora uma vez que não dispõe de quadro branco, mesa digitadora e/ou computadores, câmera, microfone entre outros recursos para a realização das aulas, alguns não dispõem de internet por morar em uma região da aldeia que não tem acesso a rede de internet. Outro aspecto é a formação que nem todos tiveram uma formação para uma educação digital, e nem para uma educação à distância.

\section{Considerações Finais}

O presente estudo teve como finalidade apresentar para a comunidade acadêmica a educação escolar indígena presente nas terras potiguara localizadas no litoral norte da Paraíba, destacando o Ensino Remoto em tempo de pandemia de corona vírus Covid-19. Contando com a participação colaborativa de oito professores atuante em uma escola estadual indígena localizada na aldeia brejinho zona rural de Marcação-PB.

Para que esse objetivo fosse alcançado foi feito uma revisão bibliográfica sobre o tema, buscando entender a educação escolar indígena assim como identificar os principais desafios para a realização de aulas ou atividades virtuais em tempo de pandemia. Foi feito também entrevista através de questionário online para os professores.

Deve-se destacar que os desafios da inclusão digital nas escolas públicas são grandes, das escolas indígenas são maiores, e em tempo de pandemia com o isolamento social e o ensino remoto a distância se fez necessário, no entanto as escolas, professores e estudantes não estavam preparados para esse desafio, todos tiveram que se reinventar, para superar mais esse desafio. 
Após o estudo foi possível identificar que a escola carregava consigo vários desafios, o ensino remoto é um problema de tamanho incalculável, com a realização de aulas não presenciais. Se esse já é um desafio grande para as escolas da zona urbana imagina as escolas indígenas localizadas nas aldeias.

\section{Referências}

Barcellos, Lusival. (2012) Práticas educativo-religiosas dos indígenas Potiguara da Paraíba. João Pessoa: Editora da UFPB.

Bello, S. (1988)A pesquisa em etnomatemática e a educação indígena. (1996) 4 Ed. Capinas, São Pulo: zetetike, 1996.

Brasil. (1988) Constituição (1988). Constituição da República Federativa do Brasil: promulgada em 5 de outubro de 1988. Com as alterações adotadas pelas emendas constitucionais $\mathrm{n}^{\circ}$. 1/92 a 56/2007 e pelas emendas constitucionais $\mathrm{n}^{\circ} 1$ a 6/94

Faustino, R. C. (2006) Política educacional no ano de 1990: multiculturalimo e interculturalidade na educação escolar indígena. Tese de Doutorado. UFSC. Programa de Pós-Graduação em Educação, 2006, p. 330

Gonçalves, Emily.; Mello, Fernanda. Educação Indígena. ( 2009) Disponível em: http://estagiocewk.pbworks.com/f/emily+e+fernanda.pdf. Acesso em abr. 2020.

Mercado, L. P. L. (2002) Novas tecnologias na educação: reflexões sobre a prática. Maceió, AL: EDUFAL, 207 p.

Nascimento, José Mateus do; Barcellos, Lusival. (2012) O povo Potiguara e a luta pela etnicidade. In: Nascimento, José Mateus do (Org.). Etnoeducação Potiguara Pedagogia da Existência e das Tradições. João Pessoa: Ideia, p. 11-25.

Silva, Ana Maria. (2011)O Vídeo como Recurso Didatico no Ensino de matemática. Dissertação de Mestrado Em Educação Em Ciências E Matemática - MECM. Goiânia.

Silva, Edna Lúcia da. Menezes, E. M. (2005) Pesquisa e suas classificações. 4. ed. Florianópolis: UFSC. 